\title{
An Image Processing Research Consistent with Standard Photographs to Determine Pilling Grade of Woven Fabrics
}

\author{
Abdurrahman Telli \\ Cukurova University, Department of Textile Engineering, Adana, Turkey
}

Corresponding Author: Abdurrahman Telli, atelli@cu.edu.tr

\begin{abstract}
In this study, MATLAB 2018a software was used to evaluate pilling grade of woven fabrics objectively. Experimental works were carried out on the EMPA W3 standard photographs and accordingly two woven fabrics. Equations were built based on the measurements of pill characteristics and textural parameters of these photographs with the help of curve fitting method after image processing steps. Intervals were generated for each fabric by using slope of these equations and quantitative parameters obtained from the original fabric. Furthermore, fabrics that were provided pilling formation at different test turns were evaluated subjectively by expert operators. Objective results corresponding to each parameter were analyzed comparatively with these subjective results. The developed method was successful by using mean of matrix elements from textural parameters and total area from pill characteristics.
\end{abstract}

\author{
ARTICLE HISTORY \\ Received: 29.03.2019 \\ Accepted: 03.09.2019
}

\section{KEYWORDS}

Pilling, image processing, GLCM, texture analysis, MATLAB

\section{INTRODUCTION}

Pilling is one of the most important features that provide information about fabric performance and aesthetic properties. In recent years, the increase in the use of synthetic fibers and blends has more increased the importance of pilling. Pilling is affected by a wide range of parameters such as material type, spinning technology, fabric production technology, finishing technology. The evaluation of pilling grades is usually based on rubbing fabric to fabric surfaces up to a specific turns. The tested samples are given a pilling grade by a trained and experienced expert. Pilling grades of samples are evaluated by the eye. Furthermore, this evaluation should be supported by standard photos [1-5]. Most of the time in decision making, it is difficult to obtain same results because of differences in visual perception between experts.
These assessments have significant limitations because it greatly depends on the human factor [6]. Due to these reasons, there has been an increasing interest in the determination of pilling resistance objectively with the applications of the image processing technology for a long time. Furferi et al. presented an outstanding and chronological review of the most relevant methods for pilling measurement proposed so far [7]. In general, quantitative analysis of pilling evaluation consists of surface digitization, pills segmentation, pills quantization and pills classification [8]. In these studies, calculating the pilling grade depends upon a host of measurements including pill density, pill size, pill height, and fuzz loft. There is limited available publication based on textural parameters of images [9]. However, it was seen that the classification of pilling is a major problem with this kind of works. Regression models, discriminant analysis and

To cite this article: Telli A. 2019. An image processing research consistent with standard photographs to determine pilling grade of woven fabrics. Tekstil ve Konfeksiyon 29(1), 268-276. 
artificial neural networks have been used comparing subjective methods for classification in the literature in recent years [10-12]. A significant number of studies are based on existing standard photographs. Because this system has been used for years and the new system must be compatible with them [13-20].

This paper seeks to remedy the mentioned problems by analyzing the deficiencies of literature with a new approach. This study takes into consideration both pills characteristics and texture features of the binary images among the quantization parameters. In different to earlier studies, the fabric was scanned before and after pilling. In this study, a system was tested based on the standard photographs (W3) corresponding to different pilling grades developed by EMPA according to Martindale method. Equations were built based on the measurements of pill and textural parameters of this photograph with the help of curve fitting method. Intervals were generated for each fabric by using slope of a distribution curve of these standard photographs and quantitative parameters obtained from the original fabric in the determination of the pilling grades of woven fabrics. Furthermore, fabrics that were provided pilling formation at different test turns were evaluated subjectively by expert operators. Objective results corresponding to each parameter were analyzed comparatively with these subjective results.

\section{MATERIAL AND METHOD}

Two different woven fabrics were used in this study as shown in Table 1.

"Nu-Martindale Test Instrument" was chosen to determine pilling resistance of these fabrics in compliance with TS EN ISO 12945-2. The images of fabric specimens with a diameter of $140 \mathrm{~mm}$ were obtained by digital scanner as $300 \times 300$ dpi (dots per inch) 24 bits before the process of placing in the rubbing area. The 300 dot/inch equals 11.811024 pixels $/ \mathrm{mm}$. The tests were carried out with three specimens for each type at 1000, 2000, 5000 and 7000 turns. After this process, fabric surfaces containing pills with a diameter of $90 \mathrm{~mm}$ were scanned again. To capture images with same method as standard every time, digital scanner was used. In this way, the test samples (diameter of $140 \mathrm{~mm}$ ) corresponded to approximately $1650 \times 1650$ pixels and pilling area (diameter of $90 \mathrm{~mm}$ ) in specimens corresponded to $1063 \times 1063$ pixels each time. Due to the lissajous movement, the pilling area on the fabric is prominent. However, the boundary regions of the pilling area may be damaged depending on the fabric structure due to the additional loading mass used in woven fabrics or the improper placement of the sample. According to our experiences, this situation causes negative effects on image processing. To eliminate these problems, taken images before and after in pilling were resized as $900 \times 900$ pixels by cutting from width and length at the same size. After that, the digital image processing steps have started.

\subsection{Image Quantization and Segmentation}

MATLAB R2018a software was used to evaluate pilling of woven fabrics. Figure 1 provides the steps of image quantization and segmentation. Firstly, the RGB color images of fabrics are loaded to MATLAB package program. These images are three-dimensional matrices in "900x900x3 uint8" format. After that, matrices must be two-dimensional (900x900 uint8) in order to be able to operate on them. Thus, matrices expressing the different tone of the gray consisted values ranging from 0 to 256 were generated. These matrices are transformed into a form (900 x 900 double) that will have a value between 0 and 1 . These forms of matrices were ready for texture analysis using GLCM from image processing techniques. Standard deviation filter was implemented on these matrices in the context of texture analysis [21, 22]. Histogram-fitting technique was used to compare a reasonable threshold for image segmentation [23]. In this way, all images were segmented with same thresholding value. Then, these images were segmented using Otsu's global thresholding algorithm (thresholding value $=0.49804$ ). Thus, the pills in the image were separated from the image background. Values below the specified radius were masked using close mask. This mask provides dilation followed by erosion. And, this removes pills smaller than the determined element. The same radius (shape $=$ disk radius $=4$ ) was also used to mask fabric images after pilling to provide the possibility of comparing the fabrics. Furthermore, the fabric's own fuzz and structure are not regarded as discomfort. After this phase, the negatives of images were obtained applying "invert mask" to matrices. Image processing was finished by clearing the borders of the image. And so, matrices of images have reached to "900x900 logical" format. Several statistics were derived with feature extraction from these matrices. Fabric's surface digitization, pills detection and segmentation were carried out with these procedures.

Table 1. Specifications of fabrics

\begin{tabular}{ccccc}
\hline Code & Weight $\left(\mathbf{g} / \mathbf{m}^{\mathbf{2}}\right)$ & Material & Weave & Fabric type \\
\hline 01 & 208 & $50 \%$ Polyester $50 \%$ Cotton & Plain weave & Trouser fabric \\
02 & 408 & $50 \%$ Polyester $50 \%$ Viscose & Plain weave & Crepe dressmaking fabric \\
\hline
\end{tabular}




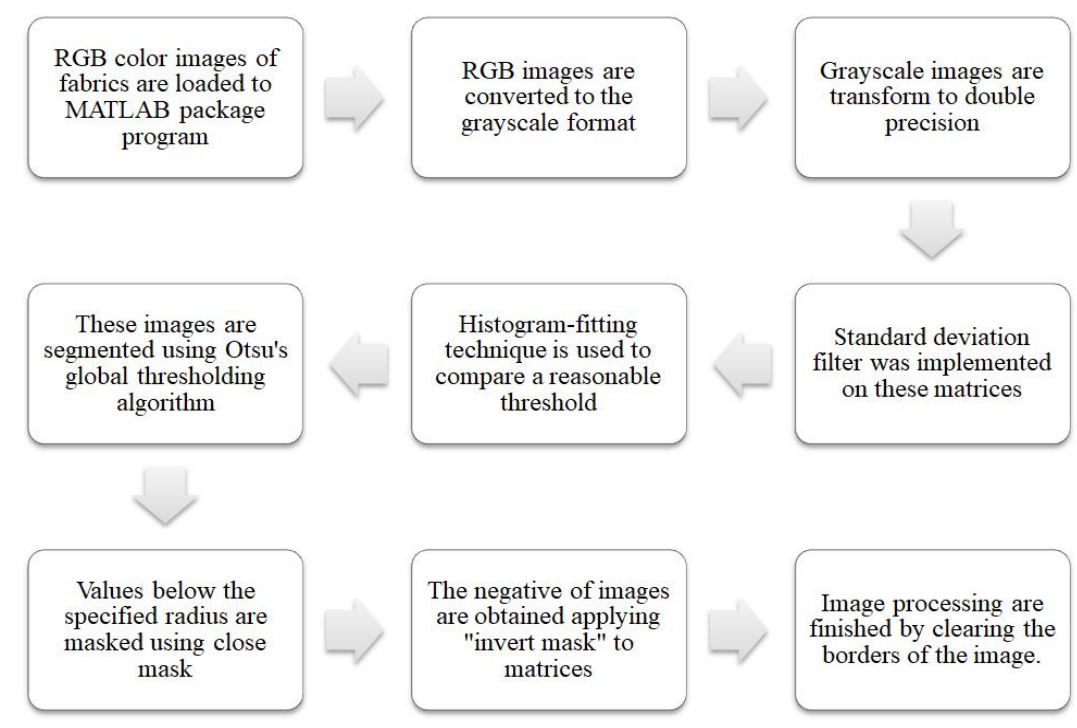

Figure 1. Steps of image quantization and segmentation

\subsection{Pills Quantizations}

Pill quantizations were made using images in matrix format obtained from image processing studies. Statistical measures were extracted from matrices. Texture analysis was performed with Gray Level Co-occurrence Matrix (GLCM). GLCM consist of contrast, correlation, energy and homogeneity. Mean of matrix elements (mean2), entropy of grayscale image (entropy) and standard deviation of matrix elements (std2) information can be obtained within texture analysis. Furthermore, it is possible to extract values from grayscale images such as pill number, area, convexArea, eccentricity, equivdiameter, Euler number, extent, filled area, major axis length, minor axis length, orientation, perimeter and solidity through image region analyzer.

\subsection{Pills Classification}

In this study, a system was tested based on the standard photographs corresponding to different pilling grades developed by EMPA. EMPA SN 198525 is an industrial standard for fabric pilling evaluation. This standard was developed for the evaluation of specimens worked in the Martindale pilling test tool. The EMPA standard contains three separate categories, each consisting of four images. In total, there are 24 photographs for knitted $(\mathrm{K} 1, \mathrm{~K} 2, \mathrm{~K} 3)$ and woven (W1, W2, W3) fabrics. In this study, experimental works were carried out on the W3 standard photograph and accordingly two woven fabrics. Equations were built based on the measurements of pill and textural parameters of these photographs with the help of curve fitting method. Intervals were generated for each fabric by using slope of a distribution curve of these standard photographs and quantitative parameters obtained from the original fabric in the determination of the pilling grades of woven fabrics. Furthermore, fabrics that were provided pilling formation at different test turns were evaluated subjectively by expert operators. Objective results corresponding to each parameter were analyzed comparatively with these subjective results.

\section{RESULTS AND DISCUSSION}

Figure 2 presents images of EMPA SN 198525 "W3" standard photographs before and after image processing. The pill quantization results obtained binary images can be compared in Table 1.

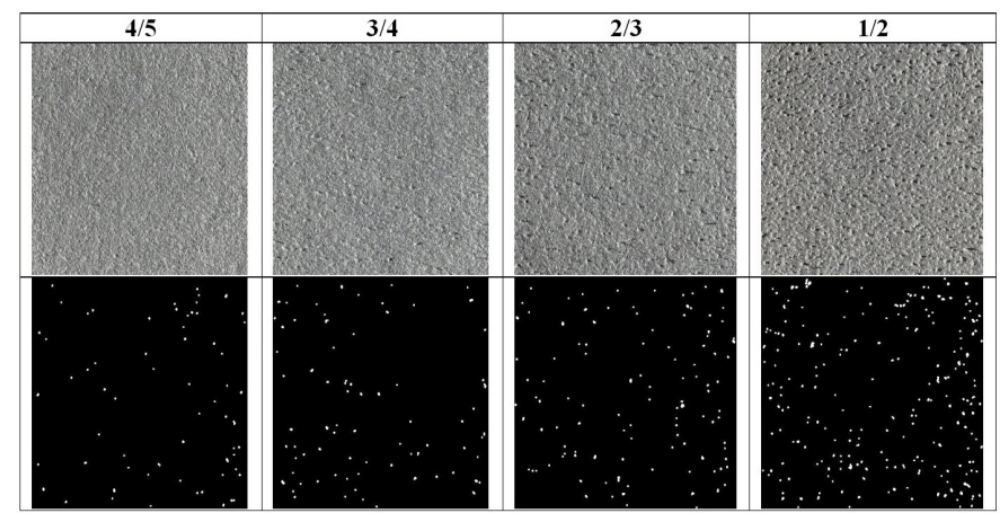

Figure 2. EMPA SN 1982555 "W3" standard photographs before and after image processing 
From Table 2, it can be seen that six features (mean of matrix elements, standard deviation of matrix elements, entropy of grayscale image, contrast, number of pills and total area) have an increasing trend when the pilling grade worse. And, two statistics (energy and homogeneity) extraction from Gray-level Co-occurrence Matrix has a reducing trend with the decrease of pilling grade. There was no clear trend between pilling grades and other variables. In these eight properties, linear curve fitting is made for each property using measuring points. As shown in Figure 3 and 4, the coefficients of the determination $\left(\mathrm{R}^{2}\right)$ for selected features was found to be $82.7 \%$ and above. Thanks to these equations, the eight intervals $(5,4 / 5,4,3 / 4$, $3,2 / 3,2,1 / 2$ ) of different pilling grades for standard photograph were generated as shown in Table 3.
The slopes of the lines obtained for each feature on the basis of these data were used for fabric samples to be tested. The extracted features from the untested fabric samples were written against the starting point of 5.25. Intervals have been generated for eight features in each fabric by using formula of the slope of the line. Then, it was investigated the intervals corresponding to values of the eight features obtained from fabrics that had pilling formation at different turns.

The results obtained from the image processing of two different woven fabrics are shown in Figure 5. Images of fabrics in 0 and 7000 turns were given in this figure.

Table 4 provides subjective evaluation results and the results of statistical measurements obtained from binary images of fabrics with feature extraction.

Table 2. The pill quantizations results obtained from "W3" standard photographs

\begin{tabular}{lcccc}
\hline \multicolumn{1}{c}{ Pilling Grade } & $\mathbf{4 / 5}$ & $\mathbf{3 / 4}$ & $\mathbf{2 / 3}$ & $\mathbf{1 / 2}$ \\
\hline Mean of matrix elements & 0.00530 & 0.00698 & 0.00961 & 0.02072 \\
Standard deviation of matrix elements & 0.07258 & 0.08328 & 0.09758 & 0.14243 \\
Entropy of grayscale image & 0.04766 & 0.06006 & 0.07822 & 0.14544 \\
Contrast & 0.00167 & 0.00210 & 0.00296 & 0.00614 \\
Correlation & 0.84205 & 0.84904 & 0.84479 & 0.84883 \\
Energy & 0.98779 & 0.98402 & 0.97799 & 0.95328 \\
Homogeneity & 0.99917 & 0.99895 & 0.99852 & 0.99693 \\
Number of Pills & 62 & 75 & 108 & 217 \\
Total Area & 4290 & 5657 & 7787 & 16780 \\
Major Axis Length & 10.3299 & 10.9462 & 10.4451 & 11.0280 \\
Minor Axis Length & 8.6400 & 8.8453 & 8.7950 & 8.9456 \\
Eccentricity & 0.3572 & 0.4097 & 0.3611 & 0.3782 \\
Orientation & 20.5863 & 7.8236 & 20.8937 & 13.4818 \\
EquivDiameter & 9.2727 & 9.6460 & 9.4151 & 9.7091 \\
Solidity & 0.9294 & 0.9299 & 0.9311 & 0.9299 \\
Extent & 0.6227 & 0.6230 & 0.6342 & 0.6249 \\
Perimeter & 28.07 & 29.47 & 28.38 & 29.73 \\
\hline
\end{tabular}
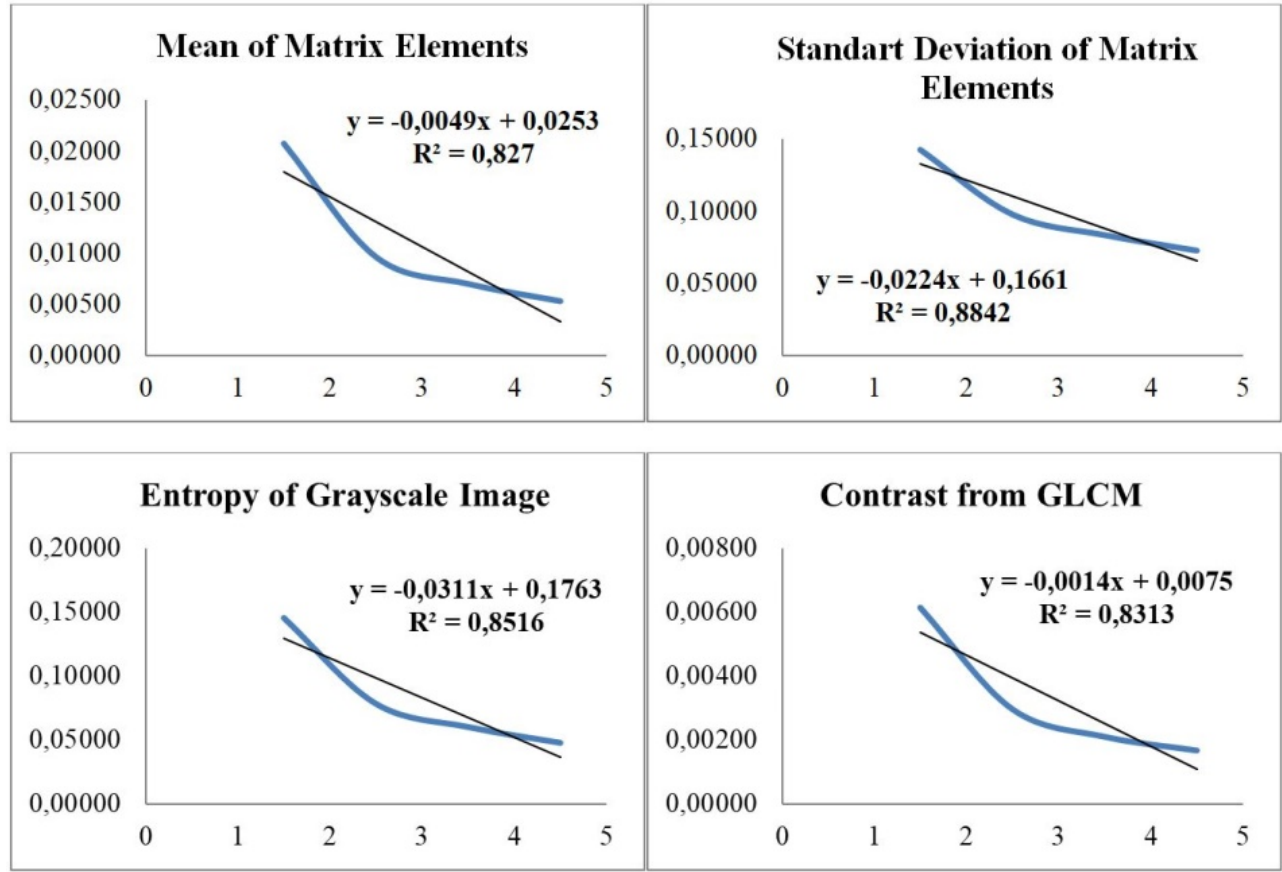

Figure 3. The obtained equations for mean, standart deviation, entropy and contrast 

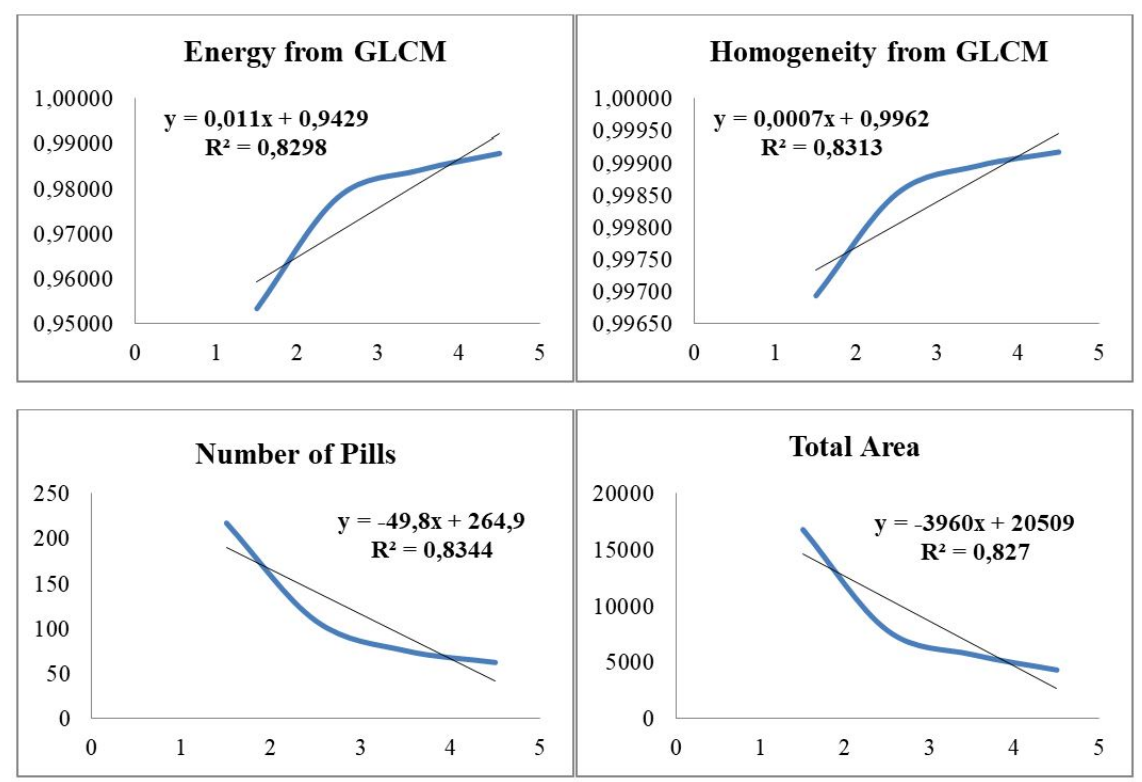

Figure 4. The obtained equations for energy, homogeneity, number of pills and total area

Table 3. The intervals of different pilling grades for standard photograph (EMPA W3)

\begin{tabular}{lccccccccc} 
& \multicolumn{1}{c}{$\mathbf{5 . 2 5}$} & $\mathbf{4 . 7 5}$ & $\mathbf{4 . 2 5}$ & $\mathbf{3 . 7 5}$ & $\mathbf{3 . 2 5}$ & $\mathbf{2 . 7 5}$ & $\mathbf{2 . 2 5}$ & $\mathbf{1 . 7 5}$ & $\mathbf{1 . 2 5}$ \\
\cline { 2 - 7 } Mean & -0.0004 & 0.0020 & 0.0045 & 0.0069 & 0.0094 & 0.0118 & 0.0143 & 0.0167 & 0.0192 \\
Std. Dev. & 0.0485 & 0.0597 & 0.0709 & 0.0821 & 0.0933 & 0.1045 & 0.1157 & 0.1269 & 0.1381 \\
Entropy & 0.0130 & 0.0286 & 0.0441 & 0.0597 & 0.0752 & 0.0908 & 0.1063 & 0.1219 & 0.1374 \\
Contrast & 0.0002 & 0.0009 & 0.0016 & 0.0023 & 0.0030 & 0.0037 & 0.0044 & 0.0051 & 0.0058 \\
Energy & 1.0007 & 0.9952 & 0.9897 & 0.9842 & 0.9787 & 0.9732 & 0.9677 & 0.9622 & 0.9567 \\
Homogeneity & 0.9999 & 0.9995 & 0.9992 & 0.9988 & 0.9985 & 0.9981 & 0.9978 & 0.9974 & 0.9971 \\
Number of Pills & 3.45 & 28.35 & 53.25 & 78.15 & 103.05 & 127.95 & 152.85 & 177.75 & 202.65 \\
Total Area & -281 & 1699 & 3679 & 5659 & 7639 & 9619 & 11599 & 13579 & 15559 \\
\hline
\end{tabular}

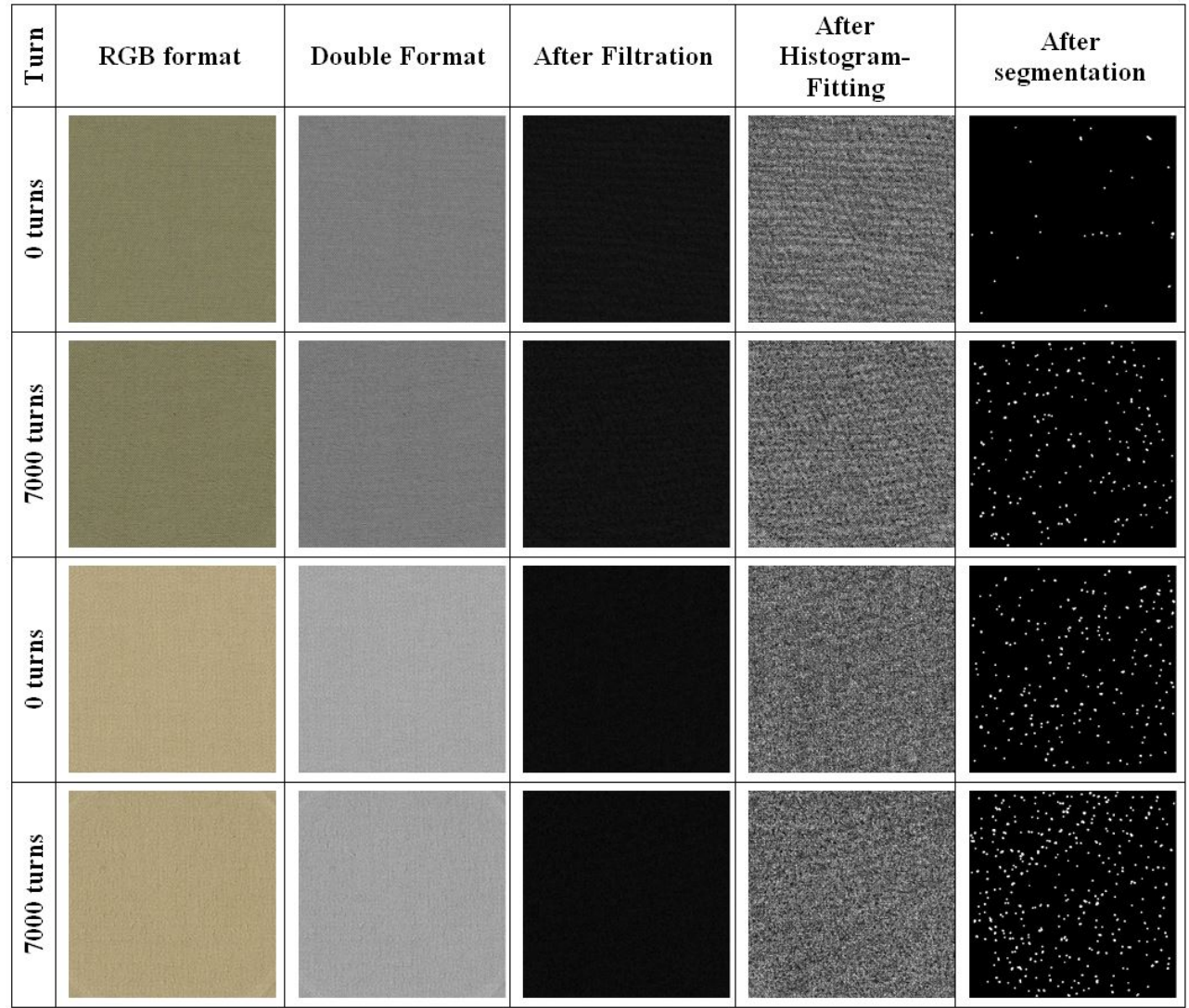

Figure 5. Images of analyzed two different fabrics in the steps of processing for 0 and 7000 turns 
Table 4. Statistical measurements obtained from binary images of fabrics with feature extraction

\begin{tabular}{|c|c|c|c|c|c|c|c|c|c|c|}
\hline 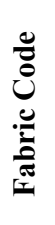 & 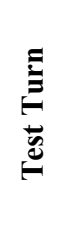 & 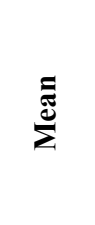 & $\begin{array}{l}\dot{\vec{D}} \\
\dot{0} \\
\dot{0}\end{array}$ & 莺 & 葡 & 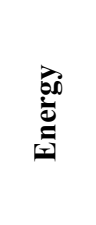 & 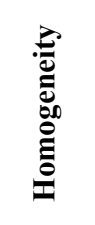 & 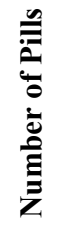 & 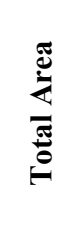 & 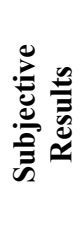 \\
\hline \multirow{5}{*}{01} & $\mathbf{0}$ & 0.0038 & 0.0606 & 0.0358 & 0.0016 & 0.9879 & 0.9992 & 43 & 3088 & - \\
\hline & 1000 & 0.0085 & 0.0918 & 0.0708 & 0.0025 & 0.9806 & 0.9987 & 96 & 6900 & $4 / 5$ \\
\hline & 2000 & 0.0111 & 0.1049 & 0.0882 & 0.0033 & 0.9747 & 0.9984 & 123 & 9016 & 4 \\
\hline & 5000 & 0.0122 & 0.1096 & 0.0949 & 0.0036 & 0.9723 & 0.9982 & 139 & 9861 & $3 / 4$ \\
\hline & 7000 & 0.0142 & 0.1180 & 0.1072 & 0.0043 & 0.9678 & 0.9979 & 162 & 11485 & 3 \\
\hline \multirow{5}{*}{02} & 0 & 0.0177 & 0.1318 & 0.1283 & 0.0054 & 0.9598 & 0.9973 & 204 & 14338 & - \\
\hline & 1000 & 0.0228 & 0.1491 & 0.1567 & 0.0067 & 0.9488 & 0.9966 & 246 & 18451 & 4 \\
\hline & 2000 & 0.0264 & 0.1601 & 0.1757 & 0.0078 & 0.9409 & 0.9961 & 284 & 21345 & $3 / 4$ \\
\hline & 5000 & 0.0314 & 0.1743 & 0.2012 & 0.0090 & 0.9302 & 0.9955 & 325 & 25415 & $2 / 3$ \\
\hline & 7000 & 0.0330 & 0.1787 & 0.2093 & 0.0094 & 0.9268 & 0.9953 & 334 & 26737 & 2 \\
\hline
\end{tabular}

It is apparent from Table 4 that subjective pilling grades have a decreasing trend with the increase of turns for both fabrics. From the data in Table 4, it can be seen that six features (mean of matrix elements, standard deviation of matrix elements, entropy of grayscale image, contrast, number of pills and total area) have an increasing trend with the worse pilling grade and the increase of test turns. And, there was a clear trend of decreasing with the increase of turns and decrease of pilling grade in two statistics (energy and homogeneity) extraction from Gray-level Cooccurrence Matrix. Data from this table can be compared with the pill quantizations results obtained from "W3" standard photographs in Table 2 which show same trends for eight features. The results indicate that eight statistical values show similarity as direction with the relationship trend between variables and pilling grades in standard photographs. However, results of the pill quantizations obtained from statistical features of both fabrics and "W3" were different in the same subjective results. The subjective results of fabric coded as "01" after 2000 turns and fabric coded as "02" after 1000 turns were equal to "4". The subjective results of fabric coded as "01" after 5000 turns and fabric coded as "02" after 2000 turns were equal to "3/4". However, the obtained eight statistical results were completely different (Table 4). Furthermore, it can be seen from Figure 6 that binary images after segmentation corresponding to same subjective results were completely different. Similar situations were observed when binary images were analyzed after segmentation in Figure 5. There were also significant increases in amounts of pills in 7000 turns according to 0 turns for both fabrics. The appearance of the fabric codes as "01" after 7000 turns were similar to the appearance of the fabric codes as "02" after 0 turns.

Very different images can be observed for the same subjective result although fabrics were used the same image processing steps and were segmented at the same diameter. In the literature, the results obtained from extracted from binary images were used directly for classification. As explained by the examples, this situation prevents reaching the correct result since the structure of each fabric is different from each other. Fabrics have different amounts of fuzz or surface properties. To eliminate this limitation of work, the data belongs to original fabrics ( 0 turns) were approved as reference point. The extracted features from the untested fabric samples were written against the starting point of 5.25. Intervals have been generated for eight features in each fabric by using formula of the slope of the line from the intervals of different pilling grades for standard photograph (EMPA W3) in Table 3. Tables 5 and 6 present the intervals of different pilling grades for fabric coded as " 01 " and "02". To give an example, let's examine how 3.75 and 3.25 intervals were generated for the 3.5 pilling grade value in statistics of number of pills from Table 5 .

\begin{tabular}{|c|c|c|c|c|}
\hline $\begin{array}{l}\text { Subjective } \\
\text { Results }\end{array}$ & 4 & 4 & $3 / 4$ & $3 / 4$ \\
\hline $\begin{array}{l}\text { Binary } \\
\text { Images after } \\
\text { segmentation }\end{array}$ & & & & \\
\hline Definition & $\begin{array}{l}\text { "01" after } 2000 \\
\text { turns }\end{array}$ & $\begin{array}{l}\text { "02" after } 1000 \\
\text { turns }\end{array}$ & $\begin{array}{c}\text { "01" after } 5000 \\
\text { turns }\end{array}$ & $\begin{array}{l}02 " \text { after } 2000 \\
\text { turns }\end{array}$ \\
\hline
\end{tabular}

Figure 6. Binary images after segmentation corresponding to "4" or "3/4" 
Table 5. The intervals of different pilling grades for fabric coded as " 01 "

\begin{tabular}{|c|c|c|c|c|c|c|c|c|c|}
\hline & 5.25 & 4.75 & 4.25 & 3.75 & 3.25 & 2.75 & 2.25 & 1.75 & 1.25 \\
\hline Mean & 0.0038 & 0.0063 & 0.0087 & 0.0112 & 0.0136 & 0.0161 & 0.0185 & 0.0210 & 0.0234 \\
\hline Std. Dev. & 0.0606 & 0.0718 & 0.0830 & 0.0942 & 0.1054 & 0.1166 & 0.1278 & 0.1390 & 0.1502 \\
\hline Entropy & 0.0358 & 0.0513 & 0.0669 & 0.0824 & 0.0980 & 0.1135 & 0.1291 & 0.1446 & 0.1602 \\
\hline Contrast & 0.0016 & 0.0023 & 0.0030 & 0.0037 & 0.0044 & 0.0051 & 0.0058 & 0.0065 & 0.0072 \\
\hline Energy & 0.9879 & 0.9824 & 0.9769 & 0.9714 & 0.9659 & 0.9604 & 0.9549 & 0.9494 & 0.9439 \\
\hline Homogeneity & 0.9992 & 0.9989 & 0.9985 & 0.9982 & 0.9978 & 0.9975 & 0.9971 & 0.9968 & 0.9964 \\
\hline Number of Pills & 43 & 68 & 93 & 118 & 143 & 168 & 193 & 218 & 243 \\
\hline Total Area & 3088 & 5068 & 7048 & 9028 & 11008 & 12988 & 14968 & 16948 & 18928 \\
\hline
\end{tabular}

Formula of slope of the line $\rightarrow \mathrm{m}=\left(\mathrm{y}_{2}-\mathrm{y}_{1}\right) /\left(\mathrm{x}_{2}-\mathrm{x}_{1}\right)$

$(103.05-3.45) /(3.75-5.25)=\left(\mathrm{y}_{2}-43\right) /(3.75-5.25)$

The slope between the values of " 5.25 " and " 3.75 " in Table 3 has remained constant for Table 5 .

The result of " 5.25 " for number of pills in Table 3 was “3.45".

The result of " 3.75 " for number of pills in Table 3 was "78.15".

The result of " 3.25 " for number of pills in Table 3 was "103.05".

The results of original fabrics ( 0 turns) were used for the initial value of 5.25 in Table 5 .

The result of original fabrics ( 0 turns) for number of pills in Table 4 was " 43 ".

In the light of this information, for " 3.75 " in statistics of number of pills from "Formula 1":

$(78.15-3.45) /(3.75-5.25)=\left(\mathrm{y}_{2}-43\right) /(3.75-5.25)$

$\mathrm{y}_{2}=118$

For " 3.25 " in statistics of number of pills from "Formula 1":

$\mathrm{y}_{2}=143$

In this case, an interval for the 3.5 pilling grade value of number of pills was generated to $118-143$ as shown in Table 5. The same operations were repeated for the other values and statistical properties.

Statistical measurements obtained from binary images of fabrics with feature extraction in Table 4 were processed on the intervals of different pilling grades for fabrics in Tables 5 and 6 . These objective results can be compared in Table 7. The same results with subjective results were painted with bold. Furthermore, 0.5 unit differences have added in addition to the same grades with the decrease of sensitivity. These similar results with subjective results were shown in a sub-color (Table 7).

In general, the relationship of similar grades among test results was compatible except standard deviation of matrix elements in "5000" and " $7000 "$ turns for fabric coded as " 02 ". However, there were significant differences in same grades. The increase of sensitivity has provided significant decrease in similarities for most of statistical properties.

Table 6. The intervals of different pilling grades for fabric coded as " 02 "

\begin{tabular}{lccccccccc} 
& $\mathbf{5 . 2 5}$ & $\mathbf{4 . 7 5}$ & $\mathbf{4 . 2 5}$ & $\mathbf{3 . 7 5}$ & $\mathbf{3 . 2 5}$ & $\mathbf{2 . 7 5}$ & $\mathbf{2 . 2 5}$ & $\mathbf{1 . 7 5}$ & $\mathbf{1 . 2 5}$ \\
\hline Mean & 0.0177 & 0.0202 & 0.0226 & 0.0251 & 0.0275 & 0.0300 & 0.0324 & 0.0349 & 0.0373 \\
Std. Dev. & 0.1318 & 0.1430 & 0.1542 & 0.1654 & 0.1766 & 0.1878 & 0.1990 & 0.2102 & 0.2214 \\
Entropy & 0.1283 & 0.1438 & 0.1594 & 0.1749 & 0.1905 & 0.2060 & 0.2216 & 0.2371 & 0.2527 \\
Contrast & 0.0054 & 0.0061 & 0.0068 & 0.0075 & 0.0082 & 0.0089 & 0.0096 & 0.0103 & 0.0110 \\
Energy & 0.9598 & 0.9543 & 0.9488 & 0.9433 & 0.9378 & 0.9323 & 0.9268 & 0.9213 & 0.9158 \\
Homogeneity & 0.9973 & 0.9970 & 0.9966 & 0.9963 & 0.9959 & 0.9956 & 0.9952 & 0.9949 & 0.9945 \\
Number of Pills & 204 & 229 & 254 & 279 & 304 & 329 & 353 & 378 \\
Total Area & 14338 & 16318 & 18298 & 20278 & 22258 & 24238 & 26218 & 28198 & 30178 \\
\hline
\end{tabular}

Table 7. The comparison of subjective and objective results

\begin{tabular}{|c|c|c|c|c|c|c|c|c|}
\hline \multirow{2}{*}{$\begin{array}{c}\text { Fabrics } \\
\text { Turns }\end{array}$} & \multicolumn{4}{|c|}{01} & \multicolumn{4}{|c|}{02} \\
\hline & 1000 & 2000 & 5000 & 7000 & 1000 & 2000 & 5000 & 7000 \\
\hline Subjective Results & 4.5 & 4 & 3.5 & 3 & 4 & 3.5 & 2.5 & 2 \\
\hline Mean & 4.5 & 4 & 3.5 & 3 & 4 & 3.5 & 2.5 & 2 \\
\hline Std. Dev. & 4 & 3.5 & 3 & 2.5 & 4.5 & 4 & 3.5 & 3 \\
\hline Entropy & 4 & 3.5 & 3.5 & 3.5 & 4.5 & 3.5 & 3 & 2.5 \\
\hline Contrast & 4.5 & 4 & 4 & 3.5 & 4.5 & 3.5 & 2.5 & 2.5 \\
\hline Energy & 4.5 & 4 & 4 & 3.5 & 4.5 & 3.5 & 2.5 & 2 \\
\hline Homogeneity & 4.5 & 4 & 3.5 & 3.5 & 4.5 & 3.5 & 2.5 & 2.5 \\
\hline Number of Pills & 4 & 3.5 & 3.5 & 3 & 4.5 & 3.5 & 3 & 2.5 \\
\hline Total Area & 4.5 & 4 & 3.5 & 3 & 4 & 3.5 & 2.5 & 2 \\
\hline
\end{tabular}


The same grades between subjective results and the results of standard deviation of matrix elements were not obtained for any turns in two different fabrics. In entropy of grayscale image, same grades were only measured " 5000 " turns for fabric " 01 " and " 2000 " turns for fabric " 02 ". In number of pills, there were two same grades in " 5000 " and "7000" turns for fabric " 01 ". One same grade was observed in "2000" turns for fabric " 02 ". In contrast, four same grades as total were determined for two fabrics. In homogeneity and energy results, five same grades as total were observed for two fabrics. The best relationships were obtained in mean of matrix elements and total area. According to Table 6, there were same grades in all turns for two fabrics with respect to mean of matrix elements and total area. It can be seen from the data in Table 7 that no differences were found in mean and total area between subjective and objective pilling grades. The developed method in this study in order to determine the fabric pilling was successful by using mean of matrix elements and total area.

A strong relationship between total area and subjective results has been reported in the literature [13, 15, 16, 23]. This study confirms that total area from pilling characteristics is associated with subjective assessments. In reviewing previous studies, no data found on the association between mean of matrix elements from textural parameters and subjective results. In addition to earlier findings, a strong relationship was observed between subjective assessments and mean of matrix elements obtained from textural parameters. There were no differences between subjective assessments and the obtained objective results by using mean of matrix elements and total area. Moreover, the developed method in this study was compatible with the current method used in the sector.

\section{CONCLUSION}

A common quality language is very important for the textile industry in the globalizing world. The most frequently fabric pilling evaluation systems are very subjective and have a broad quality interval. Differences in visual perception between operators make difficult to obtain same results. Disputes occur between some operators in the samples especially containing loosely entangled fuzz fibers. This situation often leads to disagreements in high costs in the supply chain. In this investigation, the purpose was to evaluate pilling grade of fabrics objectively with a new approach. The developed method was successful by using mean of matrix elements from textural parameters and total area from pill characteristics. The findings of the study were consistent with EMPA W3 standard photograph. In future works, the developed method should be carried out on the other EMPA or different standard photographs (BS, ASTM, IWS, M\&S and etc.) in order to be made applicable to the whole sector.

\section{REFERENCES}

1. Ukponmwan JO, Mukhopadhyay A, Chatterjee KN. 1998. Pilling. Textile progress 28(3), 1-57.

2. Özdil N. 2003. Kumaşlarda fiziksel kalite kontrol yöntemleri, E.Ü Tekstil ve Konfeksiyon Araştırma Uygulama Merkezi Yayınları Yayın No: 21, ISBN No: 975-483-579-9, Bornova-İzmir, 120s.

3. Özçelik G. 2009. Kumaş boncuklanma özelliğinin objektif olarak değerlendirilmesi ve tahminlenmesi üzerine bir araştırma, E.Ü. Fen Bilimleri Enstitüsü Doktora Tezi, Bornova-İzmir, 291s.

4. Kayseri GÖ, Kirtay E. 2015. Part 1. Predicting the pilling tendency of the cotton interlock knitted fabrics by regression analysis. Journal of Engineered Fibers and Fabrics 10(3), 155892501501000305.

5. Kayseri GÖ, Kirtay E. 2015. Part II. Predicting the pilling tendency of the cotton interlock knitted fabrics by artificial neural network. Journal of Engineered Fibers and Fabrics 10(4), 155892501501000417.

6. Telli A. 2015, April. The reliability of subjective assessment in the determination of pilling resistance of knitted fabrics, $4^{\text {th }}$ International Mediterranean Science and Engineering Congress (IMSEC 2019), 420-422.

7. Furferi R, Governi L, Volpe Y. 2015. Machine vision-based pilling assessment: a review. Journal of Engineered Fibers and Fabrics 10(3), 155892501501000320.

8. Wong C. (Ed.). 2017. Applications of Computer Vision in Fashion and Textiles. Woodhead Publishing.
9. Eldessouki M, Hassan M. 2015. Adaptive neuro-fuzzy system for quantitative evaluation of woven fabrics pilling resistance. Expert Systems with Applications 42(4), 2098-2113.

10. Zhang J, Wang X, Palmer S. 2007. Objective grading of fabric pilling with wavelet texture analysis. Textile Research Journal 77(11), 871879 .

11. Eldessouki M, Bukhari HA, Hassan M, Qashqary K. 2014. Integrated computer vision and soft computing system for classifying the pilling resistance of knitted fabrics. Fibres \& Textiles in Eastern Europe.

12. Techniková L, Tunák M, Janáček J. 2017. New objective system of pilling evaluation for various types of fabrics. The Journal of The Textile Institute, 108(1), 123-131.

13. Konda A, Xin LC, Takadera M, Okoshi Y, Toriumi K. 1990. Evaluation of pilling by computer image analysis. Journal of the Textile Machinery Society of Japan, 36(3), 96-107.

14. Xu B. 1997. Instrumental evaluation of fabric pilling. The Journal of the Textile Institute, 88(4), 488-500.

15. Hsi CH, Bresee RR, Annis PA. 1998. Characterizing fabric pilling by using image-analysis techniques. Part II: Comparison with visual pill ratings. Journal of the Textile Institute, 89(1), 96-105.

16. Abril HC, Garcia-Verela MSM, Moreno YMT, Navarro RF. 1998. Automatic method based on image analysis for pilling evaluation in fabrics. Optical Engineering, 37(11), 2937-2948.

17. Kang TJ, Cho DH, Kim SM. 2004. Objective evaluation of fabric pilling using stereovision. Textile research journal 74(11), 10131017. 
18. Kim SC, Kang TJ. 2005. Image analysis of standard pilling photographs using wavelet reconstruction. Textile Research Journal 75(12), 801-811.

19. Behera BK, Madan Mohan TE. 2005. Objective measurement of pilling by image processing technique. International Journal of Clothing Science and Technology 17(5), 279-291.

20. Zhang J, Wang X, Palmer S. 2007. Objective pilling evaluation of wool fabrics. Textile Research Journal 77(12), 929-936.

21. Telli A, Özkan İ. 2018, October. The Objective Evaluation of Pilling Tendency of Knitted Fabrics Through Digital Image Processing, ITTC- $7^{\text {th }}$ International Technical Textiles Congress. 309-312.
22. Telli A, Özkan İ. 2018. Objective Measurement of Pilling Resistance in Knitted Fabrics with Image Processing Techniques. Journal of Textiles and Engineer 25(112), 313-318.

23. Xin B, Hu J, Yan H. 2002. Objective evaluation of fabric pilling using image analysis techniques. Textile Research Journal 72(12), $1057-1064$ 